\title{
The challenges of Millennium Development Goal 1 in Bongo District of the Upper East Region of Ghana
}

\author{
Juliana Abagsonema Abane ${ }^{1}$
}

Published online: 5 May 2015

(C) Springer International Publishing 2015

\begin{abstract}
Introduction Poverty reduction has received attention at different levels in the development agenda of African countries, yet the Millennium Declaration remained the most important commitment to fighting the poverty war in sub-Saharan Africa.

Methods The study adopted a qualitative approach with an indepth interview strategy to collect empirical data from the field. In all, 39 participants from the Bongo District were interviewed.

Results/Findings The findings reveal that the MDG1 in the Bongo District are challenged by several factors such as low agricultural production, local factors and cultural factors threaten the achievement of goal 1 in the district.
\end{abstract}

Keywords Extreme poverty $\cdot$ Challenges $\cdot$ Prospects

\section{Introduction}

Even though poverty reduction has received attention at different levels in the development agenda of developing nations, the Millennium Declaration remained the most important commitment to fighting the poverty war in sub-Saharan Africa. This commitment was seen as major landmark evidence on the need to make the living conditions of the poor better. Barely a year to the target deadline, evidence suggests that the achievement of the Millennium Development Goal one (1) (MDG1) face several challenges in the wake of food inse-

Juliana Abagsonema Abane

abagsonemaabane@ymail.com

1 Local Government Service Secretariat, University Post Office, Private Mail Bag. LG52, Legon, Accra curity in sub-Saharan Africa especially in Ghana. Ghana has instituted programmes such as Ghana Poverty Alleviation programme, the Ghana Poverty Reduction Strategies I and II to mitigate the poverty situation in the country yet there are still outstanding issues to be addressed towards 2015.

It has been widely accepted that Ghana has achieved the MDG1 even long before the target deadline of 2015 (UNDP 2010). This accession may be misleading because the situation fails to indicate the context variations of poverty incidence at the local level especially in the three northern regions. This clearly does not represent the local content, and this might perhaps fail to give a vivid picture of the real situation on the ground. The trends in poverty incidence in the country have performed remarkably well since 1990 , but little data exist on how poverty reduction has fed at the local level in the country. Pragmatic efforts have been made by the Government of Ghana to formulate poverty reduction strategies with the aim of achieving the Millennium Development Goals (MDGs) through the GPRS I 2003 and the GPRS II 2006 (Government of Ghana 2006a). Evidence available supports that the three Northern regions still have high levels of poverty incidence. Ghana's progress in achieving the MDGs shows that the progress has largely been mixed across indicators (MDG 2012; Fielmua and Bandie 2011)

The purpose of this study was to find out the level of performance of the MDG1 at the local level since the national aggregates failed to show the discrepancies on the situation on the ground without clear distinction between the national and local level environment. This is because situations at the local levels are relatively not the same in several respects from national averages especially in low income and less-endowed districts in Ghana, particularly the three northern regions.

\section{Methodology}

The study employed a single method approach for the collection of data. It employed the qualitative research method. 
From the methodical point of view, qualitative methodology was employed and data collection was undertaken at different levels. District assembly core staff, the sub-committee members, non-governmental organizations (NGOs) and beneficiary groups in selected economic and livelihood projects in the district. This method was suitable because it allowed participants to express their views, opinions and feelings on the research topic. In addition, the method was chosen because several studies on the Millennium Development Goals are mainly quantitative and has not provided adequate explanation to the real situation on ground at the local level.

\section{Overview of Bongo District}

Bongo District is one of the thirteen (13) municipals and districts in the Upper East Region, with Bongo Township as its district administrative capital. The district was created in 1988 under Legislative Instrument 1446 promulgating its authority. The district shares boundaries with Burkina Faso to the North, KassenaNankana East District to the West, Bolgatanga Municipal to the South West and Nabdam District to the South East. The district has seven area town councils namely Bongo, Balungu, Soe, Beo, Vea, Zorko and Namoo Area Councils (Bongo MTDP 2010).

The occupation of the people is predominantly agricultural, but few other people engaged in craft, basket weaving and shea butter picking and processing. The Bongo District has a dry savannah climate and vegetation, poor soils and irregular rainfall patterns leading to poor crop harvests and inadequate levels of food production. Agricultural production is mainly rain-fed and largely non-mechanized and is a mixture of cashcropping and subsistence food crops.

The topography and drainage of the district have serious implications for development. The rocky nature of the district makes it difficult for farming activities to be carried out. The rocks occupy almost forty percent ( $40 \%$ ) of the land size, and this has reduced drastically land holdings for farming activities hence reducing agricultural production in the district. The 2010 Population and Housing Census put the population of the district at 84,545 a growth rate of $2.8 \%$ per annum (Ghana Statistical Service 2012).

\section{Case Study Design}

A case study method helped the researcher to gather several sources of valid information in the data collection process (Yin 2003). It also allowed the study to gather in-depth description and explanation to a single case which offered deeper understanding to the topic investigated. The use of several sources of data in the study enhanced the validity and reliability of the study. The Bongo District was selected because in the 1990s, the district had poverty levels that were higher than other districts in the Upper East Region.

\section{Sample Size}

In all, the study interviewed thirty-nine (39) participants. Three (3) districts key officers namely the Planning Officer, Budget Officer and the District Coordinating Director were selected. Four (4) chairpersons from four sub-committee systems in the Bongo District Assembly made of Agricultural, Social Services, Works and Planning and Development subcommittees were used. In addition, ten (10) participants from nine decentralized departments' namely District Director of Health, District Director of Education and Girl-child education Officer and an MIS officer at the Department of Agriculture. Furthermore, one (1) Community Development Director, one (1) Water and Sanitation officer, one (1) Environmental Health and Sanitation officer were included. Statistics officer, head of the National Board on Small Scale Industries (NBSSI), Social Welfare officer all in the Bongo District. The study also included one (1) participant each from three NGOs namely World Vision, Anglican Diocesan Development and Relief Organization (ADDRO), and one coordinator from Campaign for Female Education (Camfed)-Ghana.

Also, two (2) opinion leaders made of a Catholic Priest and an Assemblyman were used. The Bongo Traditional council was represented by the queen mother and the Bonaba (Paramount Chief of Bongo). Finally, fifteen (15) participants from five (5) pro-poor beneficiary groups were selected for the study. These groups were made of craft/basket weavers, shea butter processing group, guinea fowls farmers, traders and vocational and entrepreneurial group. These participants were selected because they had benefited from pro-poor programmes that the District Assembly had developed towards the realization of the MDG1 in the district.

\section{Sampling Techniques}

Purposive sampling technique was used. The purposive sampling was used because the participants had information that could answer the research questions. The purpose of the study which sought to assess the challenges of the MDG1 needed people who were directly or indirectly linked to the implementation of the development goals in the district. Therefore, this informed the choice of the purposive sampling. This was done to target specific participants, opinion leaders, stakeholders and beneficiary groups believed to have knowledge on the progress of the MDGs in the district.

\section{Instrument of Data Collection}

The interviews were administered personally to the participants. This paved the way for probing deeper into the research topic and provided clarification of the wording of some 
questions where necessary. The interview administration was undertaken within a period of 3 months.

An interview guide with research questions was adopted from the Department of Public Administration and Health Services Management which was approved by the Institutional Review Board of the University of Ghana. The interview guide was sub-divided into five sections. Section A: Background of Respondents was aimed at getting participants demographic characteristics which included organization name, educational level, age and sex. Section B: Pro-Poor Programmes for Realizing the MDG1 in Bongo District sought to find out the factors challenging the achievement of the MDG1 in the district. The final section was aimed at getting some information on the prospects and recommendations of MDG1 in the district.

\section{Data Management}

The interview data from the field were recorded in an audio tape, and individual interviews were sorted, translated and transcribed into 4A papers. The following was how the field interviews were managed:

First, each interview was played for several times before the final write up to ensure that the data was accurate to the questions posed. The interview scripts were read several times before grouping the responses into the specific objectives of the study.

Secondly, the research used thematic analysis as a qualitative data analysis tool. The technique involved organizing the unorganized data for major themes endorsed by participants for results discussions. These transcripts were collated based on dominant themes from respondents and discussed according to their merit. This process was highly inductive because the sub-themes emerged from the data. The analysis of the primary data was based on the research questions and the objectives of the study. The categorization was done according to the themes on the interview guide.

Finally, the analysis involved detailed description of the data in a form of a narrative analysis. The analysis made use of quotations from participants to add more information and understanding to the report.

\section{Data Analysis and Discussion of Findings}

The study aimed at finding out the challenges of the MDG1 at the local level using Bongo District as a case study. The study adopted the case study design, and an in-depth interview was the main research instrument of data collection. The results of the study have been discussed in this segment of the report. The results indicate that several challenges remain fundamental to the realization of the MDG1 in the Bongo District towards 2015 . The analysis of the data shows that the challenges are more local and cultural in nature.

\section{Low Agricultural Production}

First, the analysis of the data shows that the target of halving hunger in the district is being challenged by low agriculture production in the view of 38 respondents. Agriculture output in the district is threatened by irregular rainfall, poor soil fertility, the outbreak of pests and diseases in the district. Critical analyses of the results suggest that there are more women in crop production than there are men. The percentage of farmers in the district show that 484 women engaged in crop production against $421 \mathrm{men}$ in the district. One respondent expresses the situation in the quote below:

"As for local factors most of we the men will rather leave the work and drink. As for the women they are equal to the task because the land holding is not discriminating against them, the women can go to weed as the men. I am not defending the men anyway".

Clearly, 20 respondents agreed that women involvement in agriculture is far more than men and this, they believe has daunting implications for agriculture output in the district. In the analysis of the results, it appears that men tend to leave agriculture production to women. The men though perhaps might be engaged in other activities, the absence of men in the production process may have far reaching consequences for poverty reduction in the district. Besides, 10 respondents asserted that women access to land is limited due the cultural norms that do not allow them to own land. Even though they can be given a portion of land for farming, it is only when the land is not needed for immediate use. Women access to land is also through their sons in the case where the man passes on. In this situation, she could till the land until the sons are grown enough to take full ownership of the land. Nine (9) respondents observed that the practice has the potentials of affecting agriculture production and thereby have had a significant impact on poverty reduction since women are the majority in crops and legumes production in the district. In addition, 35 respondents express that the repercussions of rain-fed agriculture have often led to high food storages during the lean season in the district and propel incidence of hunger in general.

Fifteen (15) respondents also indicated that land holding in the district is small and this has affected agriculture activities in the district as well. These respondents stated that $40 \%$ of the land in Bongo Central is occupied by rocks. As a result, farmers are mostly left with small portion of the land in between the stones to farm that is insignificant to support their large family sizes. Twenty (20) respondents said that the growth of the population is also putting pressure on the available land for both human habitation and agriculture activities. The respondents mentioned that the oncho-free zone that has vast land has been abandoned by the people due to the earlier situation in which the black fly infected people with blindness 
who lived and farm around that area. One respondent expressed this in the comment below:

"Local factor is the land, look at the rocks. Did you see them when you were coming? The portion of the land is taken over by the rocks and therefore land holding is small".

\section{Cultural Factors}

The results reveal that some cultural practices of the people in Bongo District have been described by 35 respondents to have negative consequences on poverty reduction in the district. Culture refers to the beliefs system of the people such as their values, norms, customs and traditions which affect their world view. The findings show that 35 of the respondents believed that cultural norms had a significant impact on poverty reduction programmes in the district. Four main findings emerged on cultural challenges; wealth in people, male dominance, elaborate funerals and the practice of 'tanzaaba' as some of the cultural factors that hinder the achievement of MDG1 in the Bongo District.

The analysis shows that poverty levels in the district are high because of the value placed on livestock rearing in the district. Wealth in people refers to the value the people place on livestock especially cattle in relation to other things. Twenty-five (25) respondents believe that the attachment to cattle signifies their social recognition and supremacy in the culture. Ten (10) respondents also affirm that the presence of cattle in the family shows the level of power and influence one has in the community. This world view influences how their marriages are contracted and the extent to which they would prefer to invest in cattle rather than in their children's education. Five (5) respondents view investment in livestock like cattle and small ruminants as a serious impediment for poverty reduction in the district. Although the practice is decreasing due to educational awareness programmes organized by NGOs and the district assembly, the phenomenon is worth discussing. The cultural connotation and underpinnings of the practice is still unexplained. A quote below explains this trend:

"The other factor too is that wealth, the locals prefer to invest in livestock for instance cattle and small ruminants than in investing in their children's education. Because they believe when you have large crowd of cattle it enhances your social status. So they prefer investing in cattle than sending the children to school".

From the above quote, 25 respondents said that the concept epitomizes the cultural beliefs of the people and the world view that they hold about the happenings in their environment.
Nevertheless, 10 respondents express their views that the phenomenon has the potential to militate against the achievement of the MDG1 since children under school-going age are found taking care of herds of cattle and looking malnourish in the district.

Besides wealth in people is the issue of male dominance. The 30 respondents reminisced that the society placed men higher than women in the culture which has important implications for development in the area. According to the 2010 population census, women formed more than half of the entire population of the district and yet these women are being marginalized in terms of decision-making and resource allocation. Fifteen (15) respondents interviewed described that male dominance is influenced by the socialization process of gender differentiation or gender roles in the district. In the cultural setting of the people, the belief is that women do not own landed property. Majority of the respondents (32) explained that male dominance also reflects the ownership of land in which men owned the land and women are only given access to the use of the land. Her usage of the land is determined by whether or not the man would use it. Ten (10) respondents thought this belief has impacted negatively on agriculture production in the district because there are more women into farming than men. To these respondents, male dominance correlates with preferences of male education over female education. Evidence from the field explains the issue of male dominance in the Bongo District:

"Culturally, women are not recognized in our society because we believed that they are supposed to be seen and not to be heard. Again, women in our culture do not own landed property. There is this male preference over female because it is believed that when you give birth to a female child she goes out, she marries off and then she is not in the position to help the family income as compare to that of the male".

Fifteen (15) respondents of the sampled 39 asserted that low female-child education in the area and adversely affect poverty reduction. These respondents posited that male child is seen as the 'builder of the house' and, therefore, educating a woman is seen as educating an 'outsider' or 'another house human being'. Women marginalization has been an old-aged thing in the Ghanaian society because the society believes that the woman is supposed to be seen and not to be heard. This situation affects women outputs in the district.

Related to the above finding is the issue of elaborate funerals. The data shows that $26(66.7 \%)$ of the respondents agree that funerals are contributing to poverty incidence in the district. This, according to the 26 respondents, people uses their agriculture produce to perform funerals and during the lean season hunger hits the communities in the district. The aftermath of the celebrations left the individual in hardship. 
On the other hand, there was conflict over whether funerals pose a problem to the realization of halving hunger by 2015 in the district or not. While the majority of the respondents believed that elaborate funerals are detrimental to their progress as a district, 10 respondents in the minority felt otherwise. There were 3 respondents who said that though funerals performance itself is not the problem but the wastage that is usually characterized with the performance is a concern. Evidence from the empirical data shows the two dominant views on the issue. While one view thought elaborate funerals have negative impact on poverty reduction, the other felt otherwise. The two views from the majority and minority are presented below:

"it is true that funerals too reemphasizes poverty levels but I will say that it is not limited to only women but men too and then people prefer to spend much on elaborate funerals than investing, you will see when the person was living they couldn't spent one .... as soon as the fellow dies, some kill as many as 3-4 cattle and spend so much on drinks just to show their wealth".

The majority (66.7 \%) stated that elaborate funerals have direct impact on poverty and hunger because after they have sent all their foodstuffs to perform the funerals, families are left with little foodstuff to feed their members for a short while. They argued that within some short period of time in the dry season, they are left with nothing until the next farming season which has a daunting effect on their standard of living. The expensive nature of the funerals is a serious challenge to poverty and hunger in the district.

From the minority view, this is presented below:

"No I don't think funerals causes poverty in this district rather during funerals everyone in the community contributes little towards the funeral so the owner of the funeral gets support to avoid the shame of poverty".

The results show that $13(33.3 \%)$ represented by the minority view believed that elaborate funerals performance does not have a direct effect on poverty and hunger in the district. They supported their views that since people only perform their funerals on the ground that they have resources and the community also supports them with some resources. The dynamics of this issue is that the majority said that the implication of not donating enough to the funeral is much more humiliating. According to this group, there would be name calling and this would bring 'vie' or 'yane' literally meaning 'disgrace' or 'shame' to those people.

Lastly on culture is the practice of 'tanzaaba' in the district as described by 16 respondents; this practice affects the achievement of the poverty and hunger and the development of the girl child in the Bongo District. The term 'tanzaba' literally means 'Sister-in-bed'. This is a practice that a young man could flirt with a relative who is a sister and give birth but not allowed to marry her. This sister-relationship is not between direct siblings or family members. This practice has affected a lot of young girls and women in the district and some other districts in the Upper East Region. Ten (10) respondents illustrated that the practice was a principal cause of teenage pregnancies in the district which invariably contributes to poverty levels. These respondents believed that the practice is also responsible for some form of street children in the district as children born out of this relationship are virtually left to the care of the unfortunate young girls and women who are not gainfully employed. One participant sum ups this evidence:

"We have something here even though they are curbing it. It is called tanzaba or what? The man can impregnate the woman but he cannot marry her. A boy and a girl from the same clan can become lovers because it is allowed by the culture. The girl can become pregnant and bring children here, such children who take care of them? The cycle is built and you know of third generation streetism"

\section{Prospects of Reducing Poverty and Hunger in Bongo District}

As part of the objective of the study was to find out whether there are some prospects of achieving the MDG1 in Bongo District. This section is used to discuss the results on the prospects of MDG1. Fertilizer subsidies, pro-poor programmes, infrastructure and environmental sustainability programmes, educational awareness programmes for women and young girls, active participation and involvement of women in decision-making and advocacy on out-moded cultural practices are seem as important steps towards achieving the MDG1 in the district.

First, the findings indicate that 33 respondents viewed an increase in the provision of farm implement and fertilizer subsidies as a measure that could contribute to food security and thereby reduce hunger in the area. Additionally, 5 of the respondents believed that agriculture mechanization from the traditional farming methods would support farmers in the area to reduce poverty in the district in the long run. Ten (10) out of the 33 described that the traditional hoe and cutlass cultivation used by farmers is not yielding the desired results. This they explained that the absence of fertilizer subsidies is a major cause of low harvest in the area.

Twenty-five (25) of the participants stated that current interventions in the area of the Rural Enterprise Project (REP), Northern Rural Growth Project (NRGP) and the Block Farming Concept are laudable programmes to increase agriculture 
production. According to the 25 respondents, these programmes need to be sustained to offer jobs and employment to the people. The Rural Enterprise Project is to provide entrepreneurial skills and training to the youth in the area to make them more productive and to meet the targets of full employment level in the district. Majority of the respondents identified the Rural Enterprise Project in the district as a source of employment opportunities to the youth. The Northern Rural Growth Project is also believed to have the potentials of generating employment and increase agriculture production in the area. The Northern Rural Growth Project support in credit facilities to farmers would expand their production, which could increase their output and profit margins.

Furthermore, environmental sustainability has become necessary in an attempt to reduce poverty in the district. The present climatic changes in the district demand serious measures to reclaim the environment through tree growing and planting activities. Thirty (30) of the participants were of the opinion that the tree growing programmes introduced by Savanna Accelerated Development Agency (SADA) would recapture the environment in the district. In an effort to reclaim the environment, the paramount chief of the Bongo traditional area has put measures to forestall bush burning. A fine has been imposed on anyone who sets fire to his/her farm after harvest. There is also an on-going awareness creation being carried out by the assembly on the need to preserve the environment.

Finally, the results show that thirty-seven (37) of the respondents believe that the oncho-free zone could serve as a major prospect to meeting the MDG1 in the district. The oncho-free zone is a vast land area that could be used for agriculture activities to provide food security in the district. This is because the land size in Bongo central is rocky in nature and densely populated, thus, making farming difficult and on subsistence basis.

\section{Discussions of Findings}

This part of the report is devoted to the discussions of the results of study. This section clearly discusses in detail the findings and analysis on the local and cultural challenges of the MDG1 in Bongo District. In evaluating the situation in Bongo District, it is important to state that food insecurity is prevalent in the three regions of the north. The issue is much more complex because these regions also have high incidence of poverty than the cocoa growing areas of the south. Low agriculture production in Bongo is as a result of a set of complex issues such as erratic rainfall, prolong drought, poor soil fertility and failure of the people to move away from rain-fed agriculture to irrigation or dry season farming. In line with this finding (Sachs 2003; Sachs 2005; Scott 1997; Songsore 2003) agreed that food insecurity is a threat to reducing poverty in developing countries like Ghana and especially, the three northern regions is no exception. This finding implies that the origins of poverty in sub-Saharan Africa are dominated by environmental factors such as floods, soil infertility, climatic changes and drought.

The role of culture on poverty reduction in the Bongo District is another issue in the findings. The dynamics of culture cannot be sidelined in the discussions of poverty reduction in some African countries. This assertion has been made in the poverty literature and discourse that some cultural practices among African societies have negative implication in reducing poverty (Etounga-Manguelle 2000). The analysis of the challenges of MDG1 cannot be attained without addressing issues that bothered on culture in the Bongo District. The role of culture has not received the needed attention in the poverty literature mainly due to the fact that the issue is minimal or absent in the developed countries. This finding agrees with (Guyer and Belinga 1995) that the African indigenous societies have used social accumulation of wealth in people and rights in people as symbols of power and authority. Inferring from this evidence, it means the people of Bongo District are not different from other African societies in the practice of 'wealth-in-people'.

In discussing the role of culture is the issue of elaborate funerals that has been identified as a cultural factor that impedes the progress of the MDG1 in the district. The celebration of funerals is found in most communities in Ghana and probably elsewhere. The finding indicates that funerals have the potential of undermining the progress being made in poverty and hunger reduction in the district. Even though funerals are performed across the country, funeral celebrations took much of the peoples' productive time in the district. The situation is different from other areas in the south because funeral celebrations lasted for about a week or more and this have considerable impact on the peoples' livelihood activities. In the analysis above, it means that these challenges are likely to impact negatively on the gains made on the MDG1 in the district. Nevertheless, the situation is not a hopeless one because respondents agreed that there are prospects in realizing the MDG1 in the district.

\section{Conclusion}

From the above discussions, the following conclusions can be drawn. First, local and cultural factors may affect the outcomes on the MDG1. One of such local factors are the low agricultural production, small land holding which has the potential to impact on the gains made in terms of poverty in the Bongo District. Cultural factors such as 'tanzaaba', male dominance and elaborate funerals might perhaps impede negatively on the MDG1 in the district. In effect, culture is an important component in addressing poverty in the post 2015 development agenda of Ghana especially towards addressing rural 
poverty in the country. This research paper believes that there is the need for further studies on the impact of culture and poverty reduction to understand the challenges that confront poverty reduction in the district and elsewhere in the three northern regions as well.

\section{Appendix: Interview Guide}

In-Depth interview schedule for MDG1-reducing extreme poverty and hunger adopted from the Department of Public Administration and Health Services Management, University of Ghana Business School.

\section{Section A: Background of Respondents}

Department:

Sex:

Age.

\section{Section B: Pro-Poor Programmes for Realizing the MDG1 in Bongo District}

i. What are the pro-poor programmes for realizing of the MDG1 in Bongo District?

ii. What are the specific local programmes towards achieving MDG1 in district?

\section{Section C: Progress of the MDG1 in Bongo District}

MDG1 Targets:

A. Halve, between 1990 and 2015, the proportion of people whose income is less than one dollar a day

B. Achieve full and productive employment and decent work for all, including women and young people

C. Halve, between 1990 and 2015, the proportion of people who suffer from hunger

i. Have you heard about the MDG1 in this district?

ii. What is your understanding of the content of the MDG1?

iii. What is the state of poverty in the district compared to 5 years ago

iv. What are the reasons for the present condition?

v. What are the reasons for high incidence of poverty and hunger in the district?

vi. In your opinion, will the district be able to meet the targets of the MDG1a-halving poverty by 2015 ; give reasons vii. In your opinion, will the district be able to meet the targets of MDG1b achieve full and productive employment and decent work for all, including women and young people by 2015 ? Give reasons

viii. In your opinion will the district be able to meet the targets of MDGla-halving the proportion of people who suffer from hunger by 2015 ? Give reasons

\section{Section D: Challenges that Hinder the Achievement of MDG1 in the District}

i. What are the factors constraining the realization of the MDG1?

ii. Why do you think the obstacles are there?

iii. What are the factors hindering or facilitating achievements of MDG1 at the district level

iv. What are the local factors that hinder the achievement of the MDG1 in Bongo District

v. What are the cultural factors that militate against the realization of MDG1 in Bongo District?

\section{Section E: Prospects of MDG1 in the District}

i. In your opinion are there any prospects of the MDG1 in the district?

ii. What are your recommendations for facilitating the realization of the MDG1 in Bongo District?

\section{References}

Etounga-Manguelle, D. (2000). Does Africa need a cultural adjustment program? In L. E Harrison, S. P Huntington (Eds.), Culture values shape human progress (pp. 65-77): Basic Books.

Fielmua, N., \& Bandie, B. R. D. (2011). An assessment of MDGs performance at the local level in Ghana: a case study of West Gonja district. European Journal of Social Sciences, 23(4), 614-625.

Ghana Statistical Service. (2012). 2010 Population and housing census. Ghana Statistical Service P.O Box 1098, Accra.

Government of Ghana. (2006a). Annual progress Report of the GPRS II. Accra-Ghana: NDPC, Publications, Working Paper 4703, the World Bank

Guyer, J. I., \& Belinga, M. E. (1995). Wealth in people as wealth in knowledge: accumulation \& composition in equatorial Africa. The Journal of African History, 36(01), 31-120. doi:10.1017/ 50021853700026992.

Millennium Development Goals (2012). Ghana Progress Report. Accra: United Nations Publications

Sachs, J. D. (2003). Institutions matter, but not for everything: the role of geography and resource endowments in development shouldn't be 
underestimated. In Developing world annual editions (2006/2007) (pp. 17-20). Dubuque: McGraw-Hill.

Sachs, J. D. (2005). The development challenge. In Developing world, annual editions, (2006/2007) (pp. 5-10). Dubuque: McGraw-Hill.

Scott, C. D. (1997). Poverty among small farmers under Frei and Pinochet, 1968-1986: reviewed work(s). Bulletin of Latin
American Research, 16(1), 57-69. http://www.jstor.org/stable/ 3339637. Accessed 20 Aug 2012.

Songsore, J. (2003). Regional development in Ghana: the theory and the reality. Accra: Woeli Publishing Services.

UNDP. (2010). 2008 Ghana progress report on the millennium development goals. Accra: United Nations Publications.

Yin, R. K. (2003). Case study research: design and methods. Thousand Oaks: Sage Publications, Inc. 